\title{
Maternal differences for the reaction to ergot in unfertilized hybrid rye (Secale cereale)
}

\author{
Anna Kodisch • Brigitta Schmiedchen • Jakob Eifler • Andres Gordillo • \\ Dörthe Siekmann • Franz Joachim Fromme • Michael Oberforster • Thomas Miedaner
}

Accepted: 19 January 2022 / Published online: 3 February 2022

(C) The Author(s) 2022

\begin{abstract}
Claviceps purpurea causing ergot maintains to be a problem in commercial cytoplasmic male sterile (CMS)-based hybrid rye growing. The fungal spores compete with pollen during flowering and ergot incidence is reduced in highly pollen-shedding stands. This study was carried out to identify maternal differences in ergot infection in the absence of pollen. Ten male-sterile single crosses were tested by needle and spray inoculation and kept unfertilized in up to four field sites (Germany, Austria) and three greenhouse experiments, respectively, in two years. A medium to high correlation was observed between field (needle inoculation) and greenhouse (spray inoculation) experiments. The environments (=location $\times$ year combinations) differed in their ergot severity and ergot incidence. Significant $(P \leq 0.05)$ genotypic and genotype $\times$ environment interaction variances were
\end{abstract}

A. Kodisch $\cdot$ T. Miedaner $(\bowtie)$

State Plant Breeding Institute, University of Hohenheim, Fruwirthstraße 21, 70599 Stuttgart, Germany

e-mail: miedaner@uni-hohenheim.de

B. Schmiedchen · J. Eifler · A. Gordillo

KWS LOCHOW GMBH, 29303 Bergen, Germany

D. Siekmann · F. J. Fromme

HYBRO Saatzucht GmbH \& Co. KG, Kleptow Nr. 53, 17291 Schenkenberg, Germany

\section{Oberforster}

Austrian Agency for Health and Food Safety (AGES), Institute for Sustainable Plant Production, Spargelfeldstraße 191, 1220 Vienna, Austria detected for the unfertilized male-sterile single crosses in both test systems for both traits. The single cross K_ 4 showed a significantly lower ergot severity averaged across all environments, thus being more resilient to ergot than the other genotypes. In conclusion, spray and needle inoculation are suitable for testing unfertilized male-sterile rye materials, testing across several environments (locations, years) is definitely necessary. Selection of specific females might give the potential for further reducing ergot contamination in hybrid rye in future. The frequency of such genotypes within larger breeding populations needs to be analyzed.

Keywords Claviceps purpurea $\cdot$ Maternal effect . Resistance mechanism $\cdot$ Needle inoculation $\cdot$ Ergot $\cdot$ Rye

\section{Introduction}

The plant pathogen Claviceps purpurea ((Fr.: Fr.) Tul.) is the causal fungus for a severe disease of the grass inflorescences called ergot. The fungus is distributed worldwide with a large host range containing more than 400 grass species (Wegulo \& Carlson, 2011). After infection, instead of kernels sclerotia are produced (Pažoutová, 2002) that are a compact mass of fungal mycelium with a purplish-black outside layer (Wegulo \& Carlson, 2011). The life cycle of ergot was already described in detail (Mielke, 2000; Schumann \& Uppala, 2000; Tenberge, 1999; Tudzynski et al., 1995). C. purpurea cannot penetrate through intact glumes, so, an infection is only possible at or shortly after 
flowering (Kirchhoff, 1929). Hence, cross-pollinated plants such as rye (Secale cereale L.) are particularly vulnerable to ergot (Mielke, 2000; Tudzynski et al., 1995). A high amount of pollen reduces ergot infection considerably (Kodisch et al., 2020a; Miedaner et al., 2010a; Miedaner et al., 2017; Thakur \& Williams, 1980) due to the competitive situation of pollen and spores during flowering (Miedaner \& Geiger, 2015). Cool and rainy weather conditions at flowering promote Claviceps infections because the opening of the unfertilized flowers is prolonged, pollen dispersal largely reduced and fungal infection is supported (Miedaner \& Geiger, 2015). Recommendations for preventing ergot contamination are supporting the density and homogeneity of the rye stand by agronomic measures (early seeding, high seed density, appropriate nitrogen application), avoidance of lodging, grassy weed control within and around the fields including farm tracks, and growing of less susceptible cultivars (Alderman, 2006; Betz \& Mielke, 1996; Thakur \& Williams, 1980). Because no fungicides are registered on the market for ergot control, a resistance mechanism would be beneficial. However, just a few quantitative trait loci (QTL) related to partial resistance to ergot are known in wheat. These are influencing different components of the infection process like the hormonal pathway in durum wheat (Gordon et al., 2020) or size and weight of sclerotia in bread wheat (Gordon et al., 2015).

Ergot normally does not lead to an appreciable yield reduction, but the contamination of the grain by ergot alkaloids (EAs, Florea et al., 2017) is a serious threat, because they are toxic to humans and mammals (Hulvová et al., 2013). EAs occurred frequently in several studies in different countries and among all common cereals (Beuerle et al., 2012; Schwake-Anduschus et al., 2020; Topi et al., 2017). The European Union (EU) limits for ergot sclerotia and sclerotial fragments in unprocessed cereals are set to $0.5 \mathrm{~g} / \mathrm{kg}$ for human consumption and $500 \mu \mathrm{g} / \mathrm{kg}$ for the sum of the six most common EAs (ergometrine, ergosine, ergotamine, ergocornine, $\alpha$-ergocryptine and ergocrystine) and their -inine forms on rye milling products for consumers (European Union, 2021). For infants and young children, the maximum level is $20 \mu \mathrm{g} \mathrm{EAs} / \mathrm{kg}$. As from 01.07.2024 the limits for human nutrition will be further reduced to $0.2 \mathrm{~g} / \mathrm{kg}$ on unprocessed rye and $250 \mu \mathrm{g}$ $\mathrm{EAs} / \mathrm{kg}$ on rye milling products for consumers. For animal feeding a guidance value of $1.0 \mathrm{~g} / \mathrm{kg}$ is given (European Union, 2012). So, ergot-free rye lots have a high economic impact for breeders, farmers, and milling companies.

In 2021, rye was grown on 2.1 million hectares in the EU with a production volume of 8.5 million tons. The largest producers were Germany and Poland with $73 \%$ therefrom (Eurostat, 2022). In Germany, 70-80\% of the area is grown by hybrid cultivars with increasing importance through the years (BMEL, 2021; BSL, 2020). Hybrid cultivars in rye are based on cytoplasmic-male sterility (CMS) induced by a special cytoplasm in the female parent, the male parent contributes nuclearencoded genes of restorer-to-fertility $(R f)$ that should fully restore pollen shedding of the resulting hybrids (Miedaner \& Laidig, 2019). In reality, however, restoration ability and, thus, pollen shedding ranges from poor to excellent due to the $R f$ genes used (Miedaner et al., 2005).

Besides pollen-fertility restoration, ergot infection in rye is affected by (1) morphological measures leading to a disease escape like closed flowering, small aperture angle of the glumes or a short glume opening period, (2) the ease of restoration by the female and (3) a resistance mechanism in the ovaries that has, however, not been fully proven, yet (Menzies \& Turkington, 2015; Miedaner \& Geiger, 2015). Recently, transcriptomic analyses in wheat showed that shortly after the conidia have reached the pistil, plant resistance is already activated (Boyd et al., 2020). Small, but significant differences of ergot severity were already shown for fully male-sterile entries under pollen isolation in rye (Miedaner et al., 2010b) and pearl millet (Willingale et al., 1986). To evaluate whether genetic differences occur due to the host resistance, we inoculated cytoplasmically-male sterile (CMS) rye without the availability of pollen, i.e. all flowers remained unfertilized. Our hypothesis is, that despite these extreme conditions, differences in their ergot reaction will occur that might lead in future to the detection of resistance mechanisms.

In particular, we aimed to (1) verify the role of the female parent by analyzing CMS single crosses that remain unfertilized during ergot infection, (2) partition genotypic and environmental variation and their interaction and (3) test the suitability of needle vs. spray inoculation. Ten CMS single crosses of winter rye were tested in eight field and six greenhouse trials in Germany and Austria with needle inoculation in the field and spray inoculation in the greenhouse without the availability of rye pollen in each trial. 


\section{Materials and methods}

Plant material, experimental design, and cultivation conditions

This study was conducted with ten sterile CMS - single crosses of winter rye of two inbred lines $(\mathrm{A} \times \mathrm{B})$ of the Petkus gene pool in the greenhouse and in field trials in each of three and four sites, respectively, in Germany and Austria in 2018 and 2019 (Table 1). Seeds were provided by the respective breeding companies: five CMS - single crosses by KWS LOCHOW GMBH (KWL, Bergen, Germany) (CMS_K1 - CMS_K5), and five CMS - single crosses by HYBRO Saatzucht GmbH \& Co. KG (HYBRO, Schenkenberg, Germany) (CMS_H1 - CMS_H5). The same ten CMS single crosses were evaluated in all experiments.

In the greenhouse experiments, seeds of the ten CMS single crosses were previously sown in planting trays $\left(53 \times 40 \times 9.5 \mathrm{~cm}^{3}\right)$ in September. In October, the entries were potted in a planting pot $\left(13 \times 13 \times 13 \mathrm{~cm}^{3}\right.$, volume 1,51 ) or in a Kick-Brauckmann vessel (7 1 volume, Vienna) and stored outside or in a cold greenhouse until February or April to fulfill the vernalization. In Austria (Vienna, Hagenberg), the trials were sown directly into the Kick-Brauckmann vessels. After that, the plants were handled in greenhouses. In the greenhouse experiments, the entries were grown according to a randomized complete block ( $\mathrm{RCB}$ ) design with four replications.

The field trials were grown on large-drilled plots ranging from 5.4 to $6.9 \mathrm{~m}^{2}$ (dependent on the location) in a RCB design with four replications in a chessboardlike design. Each entry plot was surrounded by four plots of a locally grown Triticale $(\times$ Triticosecale Wittm.) as border plots. In Hagenberg, the field trials were conducted without border plots due to space limitations. Sowing was done in the end of September or early in October with a kernel density of 200 kernels $\mathrm{m}^{-2}$. Application of mineral fertilizers, herbicides, growth regulators and fungicides was performed by each location in a conventional way.

Inoculation, harvesting and recorded traits

The inoculum was produced by the laboratory of Dr. B. Rodemann (Julius Kühn-Institute, Institute for Plant Protection in Field Crops and Grassland, Braunschweig, Germany) as described by Miedaner et al. (2010a). In short, C. purpurea samples were collected from Germany, Poland and Austria and isolation was done separately for each sample according to Kirchhoff (1929). Conidia for inoculation were produced on autoclaved wheat-grain medium colonized by C. purpurea. For preparing liquid inoculation, the colonized wheat was suspended in tap water by stirring on a plate stirrer for lab analysis (Ikamag®RCT, $60 \mathrm{~min}$, room temperature) and the concentration was adjusted to $3 \cdot 10^{6}$ spores $/ \mathrm{ml}$ and multiplied separately. For both approaches, three country-specific inocula (Germany, Poland, and Austria) were mixed directly before inoculation to ensure a broad ecological range of the inoculum.

In the greenhouse, spray inoculation was used during April outside the normal rye pollen season. Additionally, bagging of all ears was done shortly after heading to keep the ears unfertilized. In Hagenberg, previous bagging was not done because no other rye plants were in the greenhouse and a large distance to the next rye fields applied. At full flowering $(\mathrm{BBCH}$ $65)$, cellophane bags were removed, and the heads were inoculated by spraying with a low-volume flower sprayer. CMS rye in pollen isolation keeps the flowers open for several days and the stigma continues to grow until it reaches out of the glume. Thus, the conidia can directly be brought onto the stigma. The inoculated ears were covered by polyethylene (PE) bags right after inoculation to achieve maximum humidity for optimal infection conditions. After five days, the PE bags were exchanged by cellophane bags to guarantee that no sclerotia will be lost due to the remaining processing. The bags were sliced at the upper side to allow some aeration. Each entry was tested with 10 plants ( 5 pots $\times 2$ plants) and two ears per plant in four replications. During the season, all following ears were constantly removed. In total, 40 plants/80 ears per entry were recorded.

For inoculation of the field trials, a needle inoculation device (Fig. 1) was used at BBCH 45- BBCH 49 (Meier, 2001), when heads were still in the leaf sheath. For this, $1 \%$ pre-cooked and cooled water agar $(10 \mathrm{~g} / \mathrm{L}$, VWR International GmbH, Darmstadt, Germany) was added to the liquid spore suspension to enhance the adhesion of the spores onto the needles. Additionally, a sponge was stuck in the spaces between the needles to form a reservoir which can put more inoculum onto the plants while squeezing the needle gadget. After dipping the needle device in the inoculum solution, the inoculum was applied 
Table 1 Overview of the experiments according to country (DE = Germany, AT = Austria), location with abbreviation (abbr.), cultivation, and evaluated traits $(\mathrm{x}=$ trait recorded $)$ in 2018 and 2019

\begin{tabular}{|c|c|c|c|c|c|c|c|}
\hline Country & Location (GPS data) & Abbr. & Test system & $\begin{array}{l}\text { Ergot severity } \\
\text { (g/ear) }\end{array}$ & $\begin{array}{l}\text { Ergot incidence } \\
\text { (number/ear) }\end{array}$ & $\begin{array}{l}\text { Ear emergence } \\
(1-9)^{\text {b) }}\end{array}$ & $\begin{array}{l}\text { Plant height } \\
(\mathrm{cm})^{\mathrm{b})}\end{array}$ \\
\hline \multicolumn{4}{|c|}{ No. of environments ${ }^{\text {a) }}$ (field/greenhouse) } & $8 / 6$ & $5 / 5$ & $8 /-$ & $8 /-$ \\
\hline $\mathrm{DE}$ & Ob. Lindenhof $\left(48^{\circ} 28^{\prime} 25.5^{\prime} \mathrm{N} 9^{\circ} 18^{\prime} 17.9^{\prime \prime} \mathrm{E}\right)$ & OLI & Field & $\mathrm{X}$ & - & $\mathrm{X}$ & $\mathrm{X}$ \\
\hline $\mathrm{DE}$ & Hohenheim $\left(48^{\circ} 42^{\prime} 51.1^{\prime \prime} \mathrm{N} 9^{\circ} 12^{\prime} 31.3^{\prime \prime} \mathrm{E}\right)$ & $\mathrm{HOH}$ & Greenhouse & $\mathrm{X}$ & $X^{c)}$ & - & - \\
\hline $\mathrm{DE}$ & Petkus $\left(51^{\circ} 59^{\prime} 14^{\prime \prime} \mathrm{N} 13^{\circ} 21^{\prime} 22^{\prime \prime} \mathrm{O}\right)$ & PET & $\begin{array}{l}\text { Greenhouse, } \\
\text { Field }\end{array}$ & $\mathrm{X}$ & $\mathrm{X}$ & $\mathrm{X}$ & $\mathrm{X}$ \\
\hline $\mathrm{DE}$ & Wulfsode $\left(53^{\circ} 02^{\prime} 57.5^{\prime \prime} \mathrm{N} 10^{\circ} 14^{\prime} 51.8^{\prime \prime} \mathrm{E}\right)$ & WUL & Field & $\mathrm{X}$ & $X^{d)}$ & $\mathrm{X}$ & $\mathrm{X}$ \\
\hline AT & Hagenberg $\left(48^{\circ} 22^{\prime} 28.4^{\prime \prime} \mathrm{N} 14^{\circ} 30^{\prime} 51.2^{\prime \prime} \mathrm{E}\right)$ & HAG & Field & $\mathrm{X}$ & $\mathrm{X}$ & $\mathrm{X}$ & $\mathrm{X}$ \\
\hline AT & Wien $\left(48^{\circ} 15^{\prime} 15.3^{\prime \prime} \mathrm{N} 16^{\circ} 29^{\prime} 01.2^{\prime \prime} \mathrm{E}\right)$ & VIE & Greenhouse & $\mathrm{X}$ & $\mathrm{X}$ & - & - \\
\hline
\end{tabular}

\footnotetext{
a) Environment = location $\mathrm{x}$ year combination

b) Recorded only in field

c) 1 year (recorded in 2019)

d) 1 year (recorded in 2018)
}

to the head by several needles. This should circumvent all escape mechanisms and mechanical barriers, such that a resistance of the ovary should get detectable. After inoculation, the ears were covered immediately by paper bags to eliminate possible pollination due to foreign pollen. About 2 weeks after flowering the bags were sliced on the upper edge for a better aeration and prevention of mold. For each entry, 40 randomly collected main ears per replication from the middle of the plot were inoculated.

Ergot severity, measured as weight of sclerotia per head ( $\mathrm{g}$ ) and ergot incidence as number of sclerotia per ear were recorded as resistance traits. Additionally, ear emergence $(1-9,1=$ very late, $9=$ very early at a specific date), and plant height $(\mathrm{cm})$ were recorded in the field. Because we used non-restorer CMS rye and bagged the inoculated ears, no seed set was observed due to missing pollen.

\section{Statistical analyses}

Single-plot data were used for all analyses, i.e. data of all inoculated ears per replicate were averaged. Outlier tests were performed as described in Bernal-Vasquez et al. (2016) and detected outliers were considered as missing values. Firstly, ANOVA was conducted for each location separately and secondly combined across locations for each trait using standard procedures (Cochran \& Cox, 1957). For all ANOVAs, the effect of the factor 'genotype' was considered as fixed and the factors 'replication' and 'environment' as random. A significance level $(P)$ of 0.05 or 0.01 was applied to all statistical calculations. The estimates of ANOVA of the ratio of genotypic to phenotypic variance considering the number of replicates were used to calculate repeatability for each environment and entry-mean heritability $\left(h^{2}\right)$ considering the number of replicates and environments across all environments, respectively (Fehr, 1987). The software R (R Core Team, 2018) and R Studio (Version 3.5.1) (RStudio Team, 2016) were used to perform outlier test, ANOVAs, calculating the means, doing graphic visualization and calculating the Pearson correlation coefficient $(r)$. In the figures, the original means are reported. Multiple testing was performed by a Tukey test at $P=0.05$ as implemented in the R - Studio.

\section{Results}

Influence of environment on ergot infection

Both inoculation methods, spray and needle inoculation, showed in all environments ergot infection (Fig. 2). The single locations largely differed for their ergot severity for field and greenhouse experiments. On average, the greenhouse approach showed higher ergot contamination in both years compared to the field trials with a higher mean ergot severity in 2018 for nearly all genotypes (Table S1). In the field, slightly higher ergot 


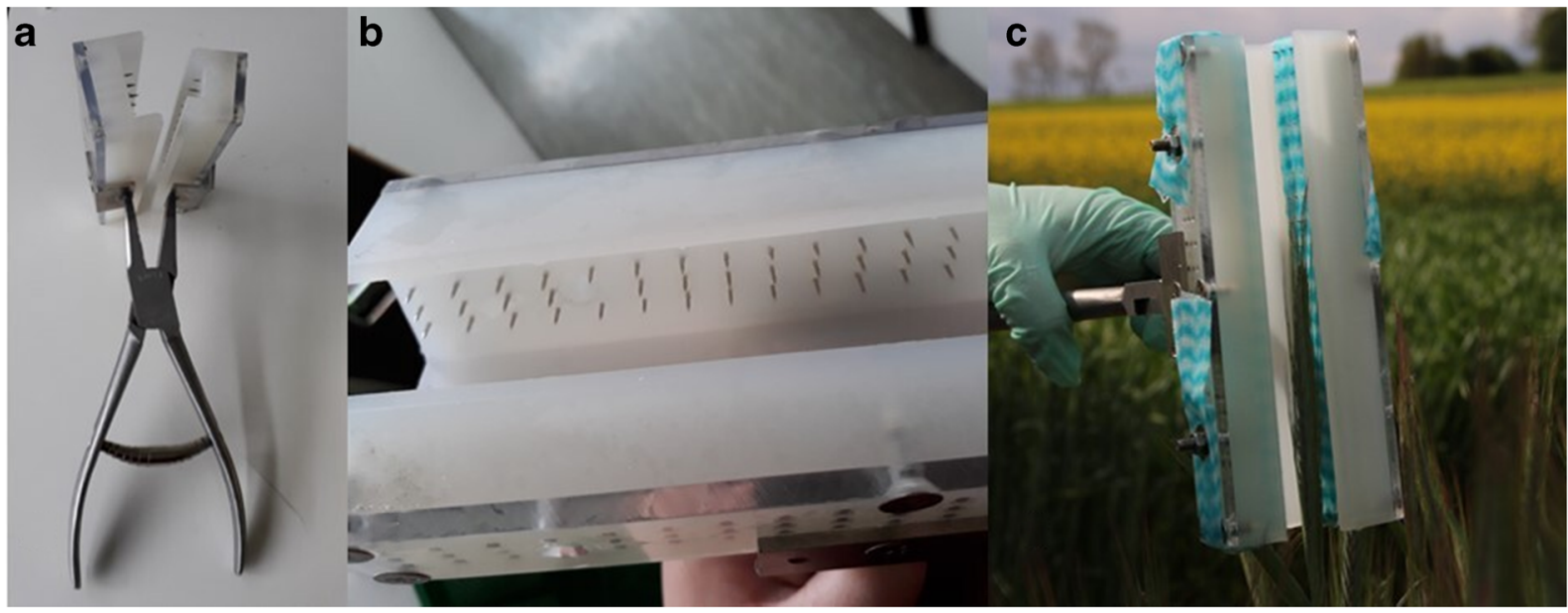

Fig. 1 Illustration of the needle inoculation device of the field trials; A plan view, B close up of the needles inside, and C: plan view with sponge (blue/white zigzag pattern) during usage in the field

severity was observed in 2019 compared to 2018 because of PET.

Influence of genotype on ergot and correlations to agronomic traits

Ergot incidence in the greenhouse was for all entries considerably higher than in the field (Table S2, S3). Mean of ergot severity and incidence of all genotypes separated by locations, years and test systems can be found in Tables S4 and S5, respectively. Although the differences were small, a good differentiation among genotypes was detected for the CMS - single crosses for both inoculation procedures and years, averaged across all locations (Table S1). Here, K_4 showed considerably the lowest ergot weight for both years and test systems. In contrast, a higher infection level was observed for K_5 and H_1 for each approach in 2018.

Correlation coefficients between greenhouse and field experiments were high in $2018(r=0.72, P<0.01)$ and moderate in 2019 ( $r=0.59$ ) (Fig. 3). When leaving out one entry $\left(\mathrm{H} \_3\right)$ that showed a large deviation from regression, the latter correlation coefficient reached $r=$ $0.84(P<0.01)$. Correlating ergot severity with ergot incidence revealed in the field a slight negative, but not significant coefficient $(r=-0.19$, Fig. S1) and in the greenhouse a high coefficient $(0.95, \mathrm{P}<0.01$, Fig. 4$)$. Ergot severity correlated also moderately with ear emergence $(r=-0.49, \mathrm{P}<0.05)$ and plant height $(r=-0.54$, $P<0.05)$ in the field. The correlations between ergot incidence and ear emergence $(r=-0.35)$ and plant height $(r=0.04)$ in the field were not significant.
Partitioning of genotypic and environmental variances

Repeatablilities of ergot severity and ergot incidence were largely varying due to locations and years (Table S6). In the combined analysis, all variance components were significantly different from zero for the main factors and their interaction for ergot severity (Table 2a) and ergot incidence (Table 2b). For the greenhouse experiments, genotype $\times$ environment interaction variance was the most important source of variation. In contrast, the environmental variance was the most relevant one for the field trials. The error variance relative to the genotypic variance was considerably lower in the greenhouse experiments than in the field experiments resulting in a higher entry-mean heritability for the greenhouse.

\section{Discussion}

Ergot infections of rye lots and accompanying contamination by toxic ergot alkaloids (EAs) is still a severe problem for food security. Current studies found only a moderate, positive correlation of ergot severity and EA content (Kodisch et al., 2020b; Schwake-Anduschus et al., 2020). Discovering a maternal resistance mechanism against ergot would have a high economic impact.

Comparison of greenhouse (spray inoculation) and field (needle inoculation) tests

Both inoculation methods and test systems resulted in considerable ergot infection. We had to weigh the 


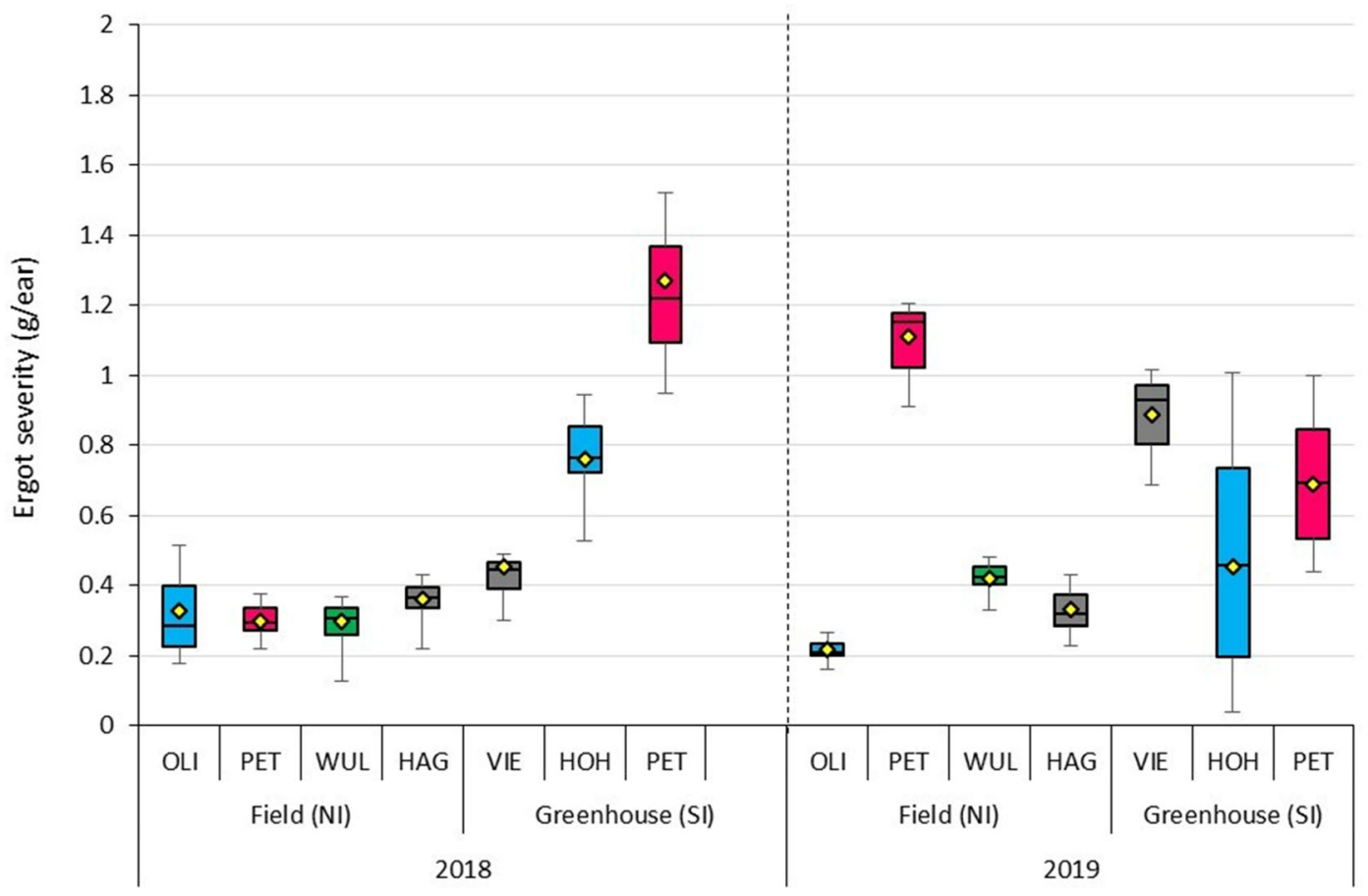

Fig. 2 Box-Whisker plots of 10 CMS single - crosses inoculated with Claviceps purpurea by needle inoculation (NI) in the field and spray inoculation (SI) in the greenhouse at three to four locations in 2018 and 2019; the boxplots show the distribution

sclerotia as resistance trait because no seed set occurred due to missing pollen. The inoculation method was confounded with the testing environment in our study, of ergot severity (black horizontal line representing the median, whiskers representing the $75 \%$ quantile, and yellow rhombus representing the mean; declaration of the abbreviations can be found in Tab 1)

because the greenhouse experiments were inoculated by spray infection and the field experiments by needle infection. We could not do a spray infection in the field

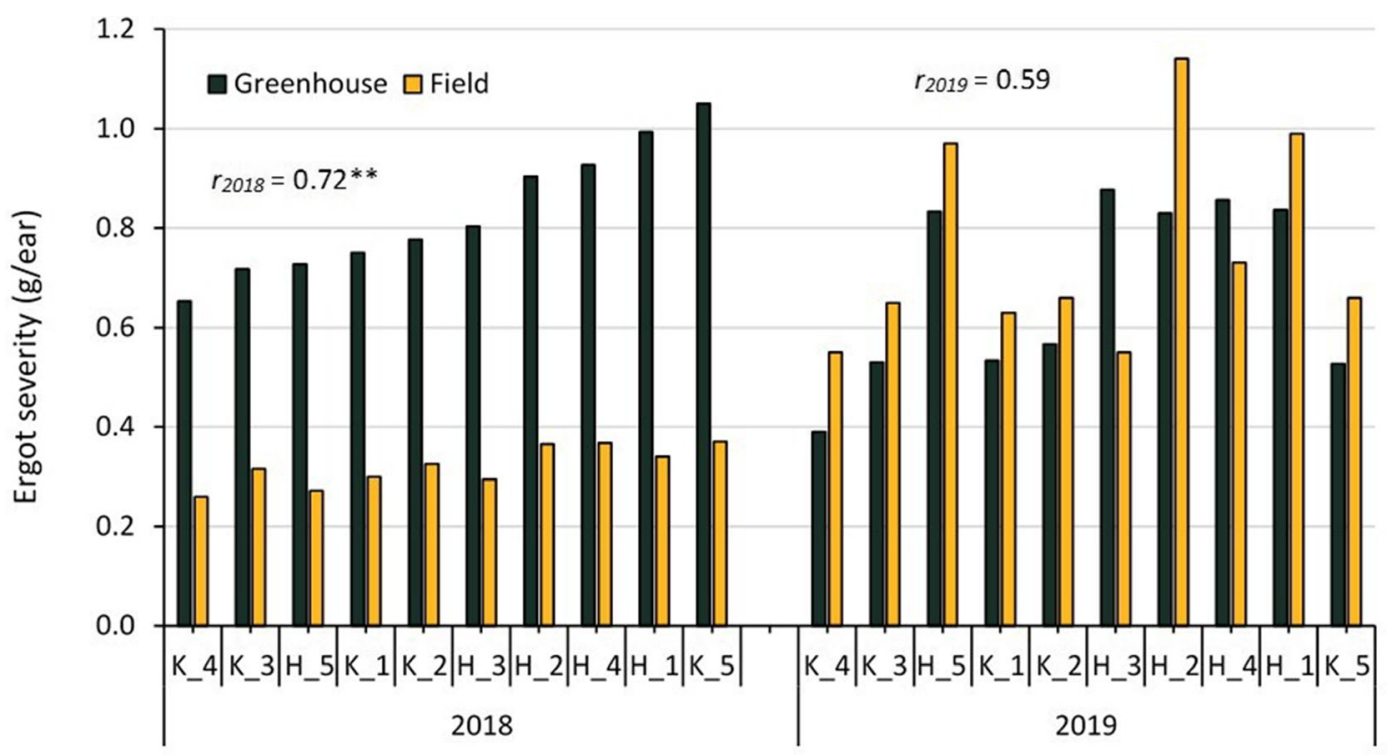

Fig. 3 Bar charts of 10 CMS single - crosses inoculated with Claviceps purpurea of ergot severity in field and greenhouse experiments at three locations in 2018 and 2019 (** significant for $P<0.01, r=$ coefficient of correlation) 


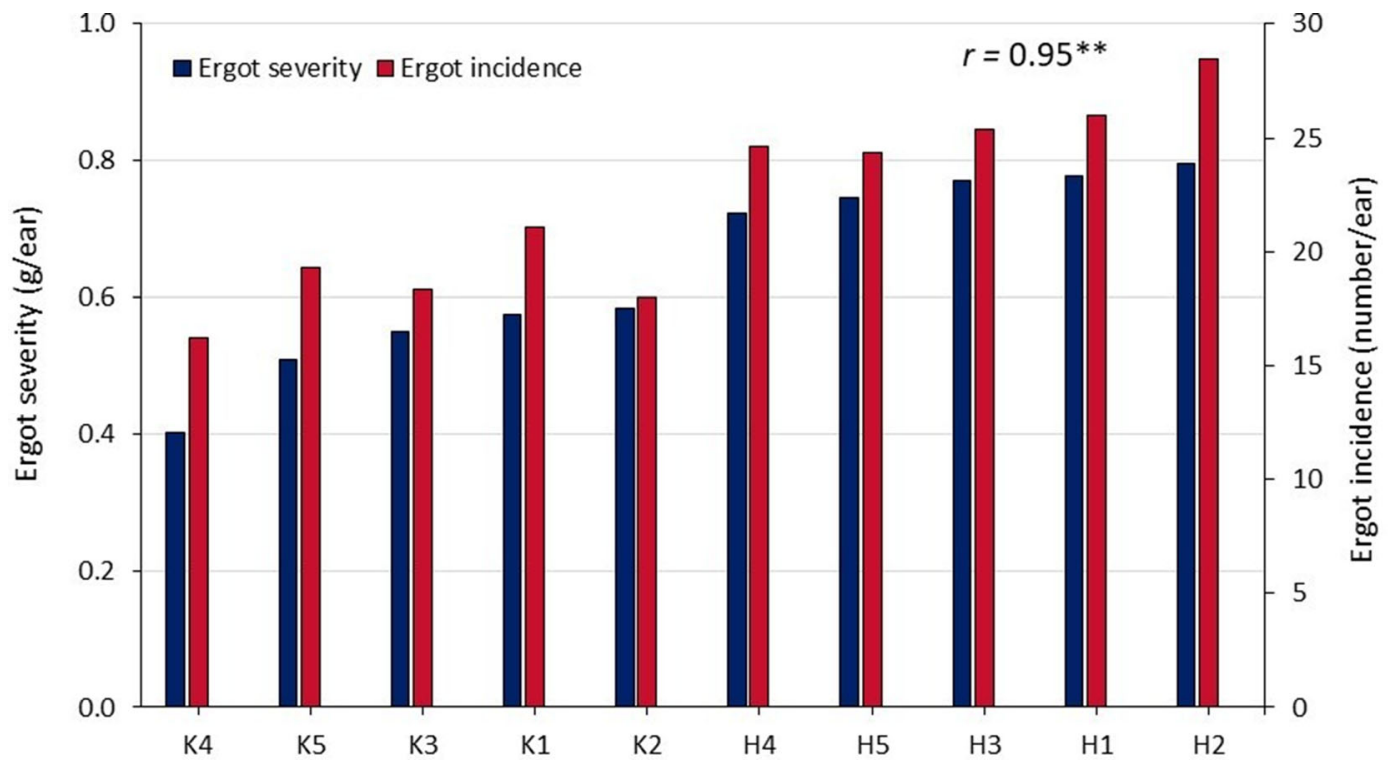

Fig. 4 Bar charts of 10 CMS single - crosses inoculated with Claviceps purpurea of ergot severity and ergot incidence in the greenhouse at three locations (HAG, PET, WUL) in 2018 and 2019 (** significant for $P<0.01, r=$ coefficient of correlation)

because of incomplete pollen isolation. Spray inoculation has to be done at full flowering when all surrounding plots are also pollen shedding. Even bagging of the inoculated heads could not inhibit fertilization, because

Table 2 Estimates of variance components and entry-mean heritabilities of 10 CMS - single crosses after inoculation by Claviceps purpurea in the greenhouse by spray inoculation (SI) the bags have to be removed for inoculation and in the meantime foreign pollen could enter the florets. The needle infection, however, is performed earlier when the heads are still in the leaf sheath and pollen shedding

and in the field by needle inoculation (NI) for a ergot severity (g/ear), and $\mathbf{b}$ ergot incidence (number/ear); (df: degrees of freedom, Var. comp.: variance components, $P$ : significance level)

\begin{tabular}{|c|c|c|c|c|c|c|}
\hline Parameter & $\mathrm{df}$ & Greenhouse (SI) & $P$ & df & Field (NI) & $P$ \\
\hline \multicolumn{7}{|l|}{ a Ergot severity } \\
\hline No. of environments ${ }^{\text {a) }}$ & & 6 & & & 8 & \\
\hline \multicolumn{7}{|l|}{ Variance components: } \\
\hline Environment (E) & 5 & 0.0093 & $* *$ & 7 & 0.0940 & $* *$ \\
\hline Genotype (G) & 9 & 0.0125 & $* *$ & 9 & 0.0041 & $* *$ \\
\hline $\mathrm{G} \times \mathrm{E}$ & 45 & 0.0242 & $* *$ & 58 & 0.0051 & $* *$ \\
\hline Error & 175 & 0.0124 & & 212 & 0.0101 & \\
\hline Heritability & & 0.73 & & & 0.66 & \\
\hline \multicolumn{7}{|l|}{ b Ergot incidence } \\
\hline No. of environments ${ }^{\text {a) }}$ & & 5 & & & 6 & \\
\hline \multicolumn{7}{|l|}{ Variance components: } \\
\hline Environment (E) & 4 & 397.6 & $* *$ & 5 & 365.8 & $* *$ \\
\hline Genotype (G) & 9 & 2497.1 & $* *$ & 9 & 93.0 & $* *$ \\
\hline $\mathrm{G} \times \mathrm{E}$ & 36 & 164.1 & $* *$ & 40 & 13.3 & $* *$ \\
\hline Error & 145 & 21.8 & & 158 & 8.4 & \\
\hline Heritability & & 0.83 & & & 0.71 & \\
\hline
\end{tabular}

\footnotetext{
** significant for $P<0.01$

a) Environment = location $\mathrm{x}$ year combinations
} 
is obviously not yet occurring. Needles deliver ergot spores directly into developing ears, where the fungus can infect unfertilized ovaries regardless of morphological factors that affect flowering.

A decisive advantage of greenhouse trials is that experiments can also be performed in the winter season and are environmentally more independent than field trials when thinking of sclerotia losses due to storm, heavy rain or drought (Duarte-Galvan et al., 2012). This is also shown by the higher heritability and the lower contribution of the environments in greenhouse. However, also here a significant genotype $\times$ environment interaction occurred. A problem with greenhouse experiments is the restricted number of genotypes that can be tested or the high investment that is necessary to test a high number of entries.

Field approaches on the other hand are more suitable to reproduce practical conditions due to realistic ambient conditions, i.e. higher density of the rye stand, more uniform development of the plants with only one to two heads per plant. The higher error of field experiments found here might also be caused by the handling of the inoculation device. For generating better heritabilities in future, the needle method can be further refined and optimized. One crucial point is inserting the ears into the device. At this, it must be ensured that all ears were punctured similarly and on the right position, so, a mounting to fix the ears would be ideally. In this context, an integrated tank for the inoculum with a direct injection system via syringe would be beneficial because the inoculum run off quickly from the pure metal. For this, a sponge was used as "inoculum reservoir" in this study. However, the needle equipment used in this experimental design seems not yet to be suitable for a large number of genotypes due to the laborious and time-consuming inoculation process. A motorized machine called "Golden hamster" (in German "Goldhamster", Putoma AG Luzern, Switzerland, Fig. S2) was developed from the pharmaceutical industry to inoculate ergot spores professionally (Barsch \& Klebs, 2017). This vehicle carried nozzles on the front side for needle inoculation and bristles for brushing off the ergot sclerotia from the ear and a collecting container on the back side for the mechanical harvesting process. With this method a "yield" of up to $600 \mathrm{~kg}$ sclerotia per hectare could be harvested on designated fields by using fully male-sterile hybrids in pollen isolation. Therefore, high-throughput technologies referring to the "Goldhamster" principle need to be considered, developed and adjusted to large-scaled ergot testing. Only the needle inoculation gives the advantage that male-fertile rye could be tested without participation of pollen, because the ears are already inoculated in the leaf sheath prior to flowering.

Nevertheless, the medium to high correlations for ergot severity between both approaches showed that the results gathered in the greenhouse can reproduce to some extent the outcome of the field and vice versa. Thus, both methods are appropriate and convertible for elaborating this kind of scientific question.

Influence of environment and agronomic traits on the ergot reaction

The tremendous role of environment and environmental interactions were already demonstrated for ergot severity (defined as the percentage of ergot sclerotia relative to the grain sample) in several previous studies (Kodisch et al., 2020a; Miedaner \& Geiger, 2015; Dhillon et al., 2010). One cause is that the infection cycle of the fungus is clearly affected by weather (Wegulo \& Carlson, 2011), another is the different flowering behavior of rye due to weather conditions. So, it is not surprising that also under pollen isolation the individual locations showed different infection levels and a large variation regarding their ergot reaction. From the variance components, the interaction of genotype by environment was the most important source of variation in the greenhouse for ergot severity. Remarkably, despite of small absolute differences, ergot severity and ergot incidence and also the differentiation among genotypes were in nearly all locations higher in the greenhouse compared to the field trials except of Petkus 2019 (Tables S3, S4, S5). The study also revealed that the factor year had a considerable high influence despite uniform handling and ambient conditions in the greenhouse. This shows once again that testing across several locations and years is definitely necessary as previously reported for other ergot resistance traits (Kodisch et al., 2020a; Miedaner et al., 2010a).

A significantly moderate negative correlation between ergot severity and plant height was previously found, whereas no correlation was reported between ergot severity and heading stage (Kodisch et al., 2020a). In this study, however, a moderate negative correlation between ergot severity and ear emergence was observed. The high positive correlation between ergot severity and incidence in the greenhouse leads to the hypothesis that highly contaminated entries contain 
a high number of ergot bodies that are associated rather with small sclerotia due to a limited sink-source relationship. Thus, the greatest threat of ergot contamination would not come from genotypes forming a few large but from those supporting many small sclerotia. These are also more difficult to detect for indent cylinder separator due to a similar size like rye grain and thus, considerably slowing down artificial sorting processes (Miedaner \& Geiger, 2015).

Genetic differences in ergot infection of unfertilized rye

Significant variation among unfertilized single crosses concerning ergot severity was observed despite of a low general infection level and a low number of genotypes. This confirms previous findings of significant differences of fully male-sterile entries under pollen isolation in rye (Miedaner et al., 2010b) and pearl millet (Willingale et al., 1986). Noticeably, in this study, the CMS-single cross with the lowest averaged ergot severity (K_4) was the same in the greenhouse as well as in the field and for both years of field testing (Fig. 3, Table S1). As a consequence, this might be an interesting candidate for further research. Thus, it is indicated that a maternal mechanism based on a resistance response of the ovary is existing because in our study the three other factors for the ergot reaction (1) influence of pollen, (2) ease of restoration of the female, and (3) morphological and/or escape mechanisms were excluded. This is supported by the fact that a significant differential gene expression at the base of the ovary was detected that included the activation of defense-related genes ahead of the arrival of the pathogen in the wheatClaviceps interaction (Boyd et al., 2020).

In conclusion, this study illustrates the existence of significant genotypic variation among unfertilized CMS-single crosses for needle and spray inoculation, a moderate relationship between both test systems and in entry $\mathrm{K}_{-} 4$ a promising candidate to further analyze maternal effects in ergot resistance. Consequently, the recurring risk of grain contamination by toxic EA (Topi et al., 2017) particularly in the light of tightened EU limits and the fact that even without visible infection in a sample toxic contamination can occur due to abrasion during handling and possible EA movement within the plant (Gordon et al., 2019) creates a need of further research on a resistance mechanism against ergot. This should include (1) to optimize the needle inoculation technique also for high-throughput applications and (2) to evaluate material for ergot resistance mechanisms with an increased set of carefully pre-selected entries and a subsequent transcriptome analysis for a deeper understanding of the underlying processes. If we aim for reducing ergot severity in rye to the level of selfpollinating crops, the maternal effects must be considered in future.

Acknowledgements The authors thank the teams at the respective locations for their excellent technical work.

Funding Open Access funding enabled and organized by Projekt DEAL. Funding was provided by Federal Ministry for Economic Affairs and Energy (Grant No. 188EN/1) and the private plant breeding companies KWS LOCHOW GMBH (Bergen, Germany) and HYBRO Saatzucht GmbH \& Co. KG (Schenkenberg, Germany). Additional support was provided by the German Society for the Promotion of Plant Innovative (GFPi, Bonn, Germany). In Austria, the funders were the Austrian Research Promotion Agency (FFG) and Saatzucht Edelhof in cooperation with Saatgut Austria. Open Access funding provided by the German DEAL contract.

\section{Declarations}

Human and animals rights No human and/or animal participants were involved in this research.

Informed consent All authors consent to this submission.

Conflict of interest The authors declare that they have no conflict of interest.

\section{References}

Alderman, S. (2006). Ergot: biology and control. Retrieved January 15, 2021, from https://www.ars.usda.gov/SP2 UserFiles/person/81/ErgotDVDtranscript.pdf

Barsch, D. \& Klebs, F. (2017). The ergot inoculation and harvesting machine "Goldhamster" [in German: Die Mutterkorn Impf- und Erntemaschine „Goldhamster"]. Retrieved January 18, 2022 from https://www.uni-hohenheim. de/117993?tx_ttnews\%5Btt_news\%5D=36083 $\& \mathrm{cHash}=92017 \mathrm{e} 0 \overline{\mathrm{a}} 93912 \mathrm{de} 06343 \mathrm{f} 30 \mathrm{c} 3 \mathrm{e} 53 \mathrm{~d} 8 \mathrm{dc}$

BSL. (2020). Descriptive variety list. Cereal, maize, large grained pulse crops, root crops (except potato). Bundessortenamt, Hannover (In German). https://www.bundessortenamt. de/bsa/media/Files/BSL/bsl_getreide_2020.pdf. Accessed 19 Jan 2021.

Bernal-Vasquez, A. M., Utz, H. F., \& Piepho, H. P. (2016). Outlier detection methods for generalized lattices: A case study on 
the transition from ANOVA to REML. Theoretical and Applied Genetics, 129, 787-804. https://doi.org/10.1007 /s00122-016-2666-6

Betz, H. G. \& Mielke, H. (1996). Possibilities to combat ergot [in German: Möglichkeiten zur Bekämpfung des Mutterkorns]. Die Mühle + Mischfuttertechnik 44, 726-728.

Beuerle, T., Benford, D., Brimer, L., Cottrill, B., Doerge, D., Dusemund, B., Farmer, P., Fürst, P., Humpf, H., \& Mulder, P. P. J. (2012). EFSA panel on contaminants in the food chain (CONTAM). Scientific opinion on ergot alkaloids in food and feed. EFSA Journal, 10, 2798-2956.

BMEL (Bundesministerium für Ernährung und Landwirtschaft). (2021). Share of rye and maslin varieties by country, p. 39. In: Besondere Ernte- und Qualitätsermittlung (BEE) 2020Reihe: Daten-Analysen. [in German: Anteil der Sorten von Roggen und Wintermenggetreide nach Ländern]. Retrieved January 18, 2022, https://www.bmel-statistik. de/fileadmin/daten/EQB-1002000-2020.pdf

Boyd, L. A., Tente, E., Ereful, N., Rodriguez, A. C., Grant, P., O'Sullivan, D. M. \& Gordon, A. (2020). Reprogramming of the wheat transcriptome in response to infection with Claviceps purpurea, the causal agent of ergot, 16 December 2020, PREPRINT (Version 1) Retrieved February 11, 2021, from Research Square. https://doi. org/10.21203/rs.3.rs-126182/v1.

Cochran, W. G., \& Cox, G. M. (1957). Experimental designs. Wiley.

Dhillon, B. S., Mirdita, V., \& Miedaner, T. (2010). Preliminary evaluation of locations for conducting selection for resistance to ergot (Claviceps purpurea) in rye. Indian Journal of Plant Genetic Resources, 23, 265-268.

Duarte-Galvan, C., Torres-Pacheco, I., Guevara-Gonzalez, R. G., Romero-Troncoso, R. J., Contreras-Medina, L. M., RiosAlcaraz, M. A. \& Millan-Almaraz, J. R. (2012). Review. Advantages and disadvantages of control theories applied in greenhouse climate control systems. Spanish Journal of Agricultural Research, 10, 926-938. https://doi.org/10.5424 /sjar/2012104-487-11.

European Union (2012). 012/154/EU: Commission Recommendation of 15 March 2012 on the monitoring of the presence of ergot alkaloids in feed and food Text with EEA relevance. Official Journal of the European Union L 77, 16.3.2012, p. 20-21. Retrieved January 18, 2022, from: http://data.europa.eu/eli/reco/2012/154/oj

European Union (2021). Commission Regulation (EU) 2021/1399 of 24 August 2021 amending Regulation (EC) No 1881/2006 as regards maximum levels of ergot sclerotia and ergot alkaloids in certain foodstuffs. Official Journal of the European Union L 301, 25.8.2021, p. 1-5. Retrieved January 18, 2022, from http://data.europa.eu/eli/reg/2021/1399/oj

Eurostat. (2022). Data Browser. Retrieved January 18, 2022, from https://ec.europa.eu/eurostat/databrowser/view/tag00049 /default/table?lang=en

Fehr, W. R. (1987). Principles of cultivar development, theory and technique (Vol. 1) Macmillan.

Florea, S., Panaccione, D. G., \& Schardl, C. L. (2017). Ergot alkaloids of the family Clavicipitaceae. Phytopathology, 107, 504-518. https://doi.org/10.1094/PHYTO-12-16-0435RVW

Gordon, A., Basler, R., Bansept-Basler, P., Fanstone, V., Harinarayan, L., Grant, P. K., Birchmore, R., Bayles, R. A.,
Boys, L. A., \& O’Sullivan, D. O. (2015). The identification of QTL controlling ergot sclerotia size in hexaploid wheat implicates a role for the $R h t$ dwarfing alleles. Theoretical and Applied Genetics, 128, 2447-2460. https://doi.org/10.1007 /s00122-015-2599-5

Gordon, A., Delamare, G., Tente, E. \& Boyd, L. (2019). Final project report: determining the routes of transmission of ergot alkaloids in cereal grains. AHDB PR603. Retrieved January 15, 2021, from https://ahdb.org.uk/determining-theroutes-of-transmission-of-ergot-alkaloids-in-cereal-grains

Gordon, A., McCartney, C., Knox, R. E., Ereful, N., Hiebert, C. W., Konkin, D. J., Hsueh, Y. C., Bhadauria, V., Sgroi, M., O’Sullivan, D. M., Hadley, C., Boyd, L. A., \& Menzies, J. (2020). Genetic and transcriptional dissection of resistance to Claviceps purpurea in the durum wheat cultivar Greenshank. Theoretical and Applied Genetics, 133, 1873-1886. https://doi.org/10.1007/s00122-020-03561-9

Hulvová, H., Galuszka, P., Frébortová, J., \& Frébort, I. (2013). Parasitic fungus Claviceps as a source for biotechnological production of ergot alkaloids. Biotechnology Advances, 31, 79-89. https://doi.org/10.1016/j.biotechadv.2012.01.005

Kirchhoff, H. (1929). Contributions to the biology and physiology of the ergot fungus [in German: Beiträge zur Biologie und Physiologie des Mutterkornpilzes]. Zentralblatt für Bakteriologie und Parasitenkunde, 77, 310-369.

Kodisch. A, Wilde, P., Schmiedchen, B., Fromme, F. J., Rodemann, B., Tratwal, A., Oberforster, M., Wieser, F., Schiemann, A., Jørgensen, L. N. \& Miedaner, T. (2020a). Ergot infection in winter rye hybrids shows differential contribution of male and female genotypes and environment. Euphytica, 216, 65. https://doi.org/10.1007/s10681-02002600-2.

Kodisch, A., Oberforster, M., Raditschnig, A., Rodemann, B., Tratwal, A., Danielewicz, J., Korbas, M., Schmiedchen, B., Eifler, J., Gordillo, A., Siekmann, D., Fromme, F. J., Wuppermann, F. N., Wieser, F., Zechner, E., Niewińska, M., \& Miedaner, T. (2020b). Covariation of ergot severity and alkaloid content measured by HPLC and one ELISA method in inoculated winter rye across three isolates and three European countries. Toxins, 12, 676. https://doi. org/10.3390/toxins 12110676

Meier, U. (2001). Growth stages of mono- and dicotyledonous plants. BBCH Monograph. Retrieved April 02, 2020, from h t t p s : / / w w w . ju li u s-kue h n . d e/media / Veroeffentlichungen/bbch\%20epaper\%20en/page.pdf

Menzies, J. G., \& Turkington, T. K. (2015). An overview of the ergot (Claviceps purpurea) issue in western Canada: Challenges and solutions. Canadian Journal of Plant Pathology, 37, 40-51. https://doi.org/10.1080 /07060661.2014.986527

Miedaner, T., \& Geiger, H. H. (2015). Biology, genetics, and management of ergot (Claviceps spp.) in rye, sorghum, and pearl millet. Toxins, 7, 659-678. https://doi.org/10.3390 /toxins 7030659

Miedaner, T. \& Laidig, F. (2019). Hybrid breeding in rye (Secale cereale L.). In J. Al-Khayri, S. Jain, D. Johnson (Eds) Advances in plant breeding strategies: Cereals. (Vol. 5, pp. 343-372). Springer. https://doi.org/10.1007/978-3-03023108-8 9 .

Miedaner, T., Wilde, P., \& Wortmann, H. (2005). Combining ability of non-adapted sources for male-fertility restoration 
in Pampa CMS of hybrid rye. Plant Breeding, 124, 39-43. https://doi.org/10.1111/j.1439-0523.2004.01038.x

Miedaner, T., Mirdita, V., Rodemann, B., Drobeck, T., \& Rentel, D. (2010a). Genetic variation of winter rye cultivars for their ergot (Claviceps purpurea) reaction tested in a field design with minimized interplot interference. Plant Breeding, 129, 58-62. https://doi.org/10.1111/j.1439-0523.2009.01646.x

Miedaner, T., Dänicke, S., Schmiedchen, B., Wilde, P., Wortmann, H., Dhillon, B. S., \& Mirdita, V. (2010b). Genetic variation for ergot (Claviceps purpurea) resistance and alkaloid concentrations in cytoplasmic-male sterile winter rye under pollen isolation. Euphytica, 173, 299-306. https://doi.org/10.1007/s10681-009-0083-5

Miedaner, T., Herter, C. P., Goßlau, H., Wilde, P., \& Hackauf, B. (2017). Correlated effects of exotic pollen-fertility restorer genes on agronomic and quality traits of hybrid rye. Plant Breeding, 136, 224-229. https://doi.org/10.1111/pbr.12456

Mielke, H. (2000). Studies on the fungus Claviceps purpurea (Fries) Tulasne considering the susceptibility of different rye cultivars [in German: Studien über den Pilz Claviceps purpurea (Fries) Tulasne unter Berücksichtigung der Anfälligkeit verschiedener Roggensorten]. Mitteilungen aus der Biologischen Bundesanstalt für Land- und Forstwirtschaft, 375.

Pažoutová, S. (2002). The evolutionary strategy of Claviceps. In: F. White, C. W. Bacon, N. L. Hywel-Jones, \& S. W. Spatafora. (Eds) Clavicipitalean fungi: Evolutionary biology, chemistry, biocontrol and cultural impacts. (pp 329-354). Marcel Dekker.

R Core Team. (2018). R: A language and environment for statistical computing. R Foundation for Statistical Computing, . ISBN 3-900051-07-0. Retrieved April 07, 2020, from https://www.R-project.org

R Studio Team. (2016). RStudio: Integrated development for $R$. RStudio, Inc., Boston. Retrieved April 07, 2020, from https://www.rstudio.com/
Schumann, G. L. \& Uppala, S. (2000). Ergot of rye. Updated 2017. The Plant Health Instructor. Retrieved January 18, 2022 from https:/www.apsnet.org/edcenter/disandpath/ fungalasco/pdlessons/Pages/Ergot.aspx

Schwake-Anduschus, C., Lorenz, N., Lahrssen-Wiederholt, M., Lauche, A., \& Dänicke, S. (2020). German monitoring 2012-2014: Ergot of Claviceps purpurea and ergot alkaloids (EA) in feeding stuffs and their toxicological relevance for animal feeding. Journal of Consumer Protection and Food Safety, 15, 321-329. https://doi.org/10.1007/s00003-02001298-7

Tenberge, K. B. (1999). Biology and life strategy of the ergot fungi. In V. Křen, L. Cvak (Eds.), Ergot: The genus Claviceps. (pp 25-56) Harwood Academic Publishers.

Thakur, R. P., \& Williams, R. J. (1980). Pollination effects on pearl millet ergot. Phytopathology, 70, 80-84. https://doi. org/10.1094/Phyto-70-80

Topi, D., Jakovac-Strajn, B., Pavšič-Vrtač, K., \& Tavčar-Kalcher, G. (2017). Occurrence of ergot alkaloids in wheat from Albania. Food Additives \& Contaminants: Part A, 34, 13331343. https://doi.org/10.1080/19440049.2017.1307528

Tudzynski, P., Tenberge, K., Oeser, B. (1995). Claviceps purpurea. In: K. Kohmoto, U. S. Singh, R. P. Singh. (Eds.) Pathogenesis and host specificity in plant diseases: Histopathological, biochemical, genetic and molecular bases (Vol. II, eukaryotes pp 161-187). Elsevier Science.

Wegulo, S. N. \& Carlson, M. P. (2011). Ergot of small grain cereals and grasses and its health effects on humans and livestock. University of Nebraska, extension, EC1880. Retrieved January 14, 2021, from https://ianrpubs.unl. edu/live/ec1880/build/ec1880.pdf

Willingale, J., Mantle, P. G., \& Thakur, R. P. (1986). Post pollination stigmatic constriction, the basis of ergot resistance in selected lines of pearl millet. Phytopathology, 76, 536-539. https://doi.org/10.1094/Phyto-76-536 